\title{
Estimate of dietary phosphorus intake using 24-h urine collection
}

\author{
Yuuka Morimoto, ${ }^{1}$ Masae Sakuma, ${ }^{1, *}$ Hiroyuki Ohta, ${ }^{1}$ Akitsu Suzuki, ${ }^{1}$ Asami Matsushita, ${ }^{1}$ Minako Umeda, ${ }^{2}$ \\ Makoto Ishikawa, ${ }^{2}$ Yutaka Taketani, ${ }^{3}$ Eiji Takeda $^{3}$ and Hidekazu Arai ${ }^{1}$ \\ ${ }^{1}$ Laboratory of Clinical Nutrition and Management, Graduate School of Nutritional and Environmental Sciences and ${ }^{2}$ School of Nursing Sciences, \\ The University of Shizuoka, 52-1 Yada, Suruga-ku, Shizuoka 422-8526, Japan \\ ${ }^{3}$ Department of Clinical Nutrition, Institute of Health Biosciences, University of Tokushima Graduate School, 3-18-15 Kuramoto, Tokushima 770-8503, Japan
}

(Received 27 January, 2014; Accepted 18 February, 2014; Published online 14 June, 2014)

\begin{abstract}
Increases in serum phosphorus levels and dietary phosphorus intake induces vascular calcification, arterial sclerosis and cardiovascular diseases. Limiting phosphorus intake is advisable, however, no assessment methods are capable of estimating dietary phosphorus intake. We hypothesized that urinary phosphorus excretion can be translated into estimation of dietary phosphorus intake, and we evaluated whether a 24-h urine collection method could estimate dietary phosphorus intake. Thirty two healthy subjects were recruited for this study. Subjects collected urine samples over $24 \mathrm{~h}$ and weighed dietary records. We calculated dietary protein intake and phosphorus intake from dietary records and urine collection, and investigated associations between the two methods in estimating protein and phosphorus intake. Significant positive correlations were observed between dietary records and UC for protein and phosphorus intake. The average intakes determined from dietary records were significantly higher than from urine collection for both protein and phosphorus. There was a significant positive correlation between both the phosphorus and protein difference in dietary records and urine collection. The phosphorus-protein ratio in urine collection was significantly higher than in dietary records. Our data indicated that the 24-h urine collection method can estimate the amount of dietary phosphorus intake, and the results were superior to estimation by weighed dietary record.
\end{abstract}

Key Words: serum phosphorus level, dietary phosphorus intake, 24-h urine collection

$\mathrm{S}$ erum phosphorus levels are usually maintained in the normal range of $2.5 \mathrm{mg} / \mathrm{dl}$ to $4.5 \mathrm{mg} / \mathrm{dl}$, however, disorders of the kidney decreases phosphorus excretion in the urine and increases serum phosphorus levels. It has been reported that an increase in serum phosphorus levels induces vascular calcification, arterial sclerosis and cardiovascular diseases. ${ }^{(1,2)}$ In addition, serum phosphorus levels and dietary phosphorus intake are associated with mortality in dialysis patients..$^{(3,4)}$ In healthy individuals, a high dietary phosphorus intake increases serum phosphorus levels ${ }^{(5)}$ and impairs endothelial function. ${ }^{(6)}$ Therefore, it is advisable that both kidney failure patients and healthy individuals should avoid having too much phosphorus.

Recently, energy and protein excesses have become a problem in Japanese diets due to westernized food habits, ${ }^{(7)}$ including intake of processed foods which have improved preservative qualities and palatability. Dietary protein is correlated with dietary phosphorus, ${ }^{(8,9)}$ and processed foods contain relatively large amounts of phosphorus as food additives. According to Japan's National Health and Nutrition Examination Survey, 2008, phosphorus consumption is approximately $970 \mathrm{mg} /$ day $^{(10)}$ : recom- mended intake amounts of phosphorus are $1,000 \mathrm{mg} /$ day for adult males and $900 \mathrm{mg}$ /day for adult females in Japan. ${ }^{(11)}$ However, this survey didn't take account of dietary phosphorus intake from food additives, so the actual dietary phosphorus intake is considered to be higher.

Weighed dietary records are used as the 'gold standard' method in assessing nutrient intake. However, previous studies have revealed that weighed dietary records often over- or underestimate food intake ${ }^{(12-14)}$ : there is no requirement for the phosphorus content in processed foods to be included on the nutrition label, ${ }^{(15)}$ and fluctuations in phosphorus content due to cooking loss, production region and picking seasons are not considered. Assessing 'true' dietary phosphorus intake is extremely difficult due to the absence of assessment methods capable of estimating dietary phosphorus intake. Development of valid assessment methods is increasingly needed.

We focused on a 24-h urine collection method. Urinary nitrogen and sodium excretions as recovery biomarkers for protein and salt intake, respectively, have been routinely used in clinical practice using 24-h urine collection. ${ }^{(16,17)}$ We hypothesized that urinary phosphorus excretion could be used to estimate dietary phosphorus intake. The purpose of this study was to evaluate whether a 24-h urine collection method could be used to estimate dietary phosphorus intake.

\section{Materials and Methods}

Subjects. Thirty two healthy subjects (14 males and 18 females) between 21 and 28 years were recruited for this study. We performed physical measurements and biochemical examinations of blood to show that subjects had no health problems. The clinical and biological characteristics of the subjects are shown in Table 1. All subjects gave informed consent and the ethical committee of the University of Shizuoka approved this study.

Protocol. Subjects performed 24-h urine collection and weighed dietary records. Subjects were asked to avoid participation in heavy exercise during the study. Subjects weren't limited in any other activities or dietary intake and were prescribed to spend a day as normal. On the following morning, subjects presented weighed dietary records, pictures of foods they consumed and 24$\mathrm{h}$ urine samples. Blood was collected from subjects after sufficient rest. Subjects participated three times in these exams with at least one day intervals.

24-h urine collection method. Subjects performed the 24-h urine collection method using URIN-MATEP (Sumitomo Chemical

*To whom correspondence should be addressed.

E-mail: sakuma@u-shizuoka-ken.ac.jp 
Table 1. Characteristics of the study subjects

\begin{tabular}{llc}
\hline Characteristic & & Mean \pm SD \\
\hline Sex & $(\mathrm{M} / \mathrm{F})$ & $14 / 18$ \\
Age & $(\mathrm{year})$ & $22.1 \pm 1.5$ \\
Body fat percentage & $(\%)$ & $21.8 \pm 5.6$ \\
Body mass index & $\left(\mathrm{kg} / \mathrm{m}^{2}\right)$ & $21.1 \pm 2.6$ \\
Triglyceride & $(\mathrm{mg} / \mathrm{dl})$ & $62.3 \pm 29.7$ \\
LDL-Cholesterol & $(\mathrm{mg} / \mathrm{dl})$ & $93.3 \pm 24.2$ \\
HDL-Cholesterol & $(\mathrm{mg} / \mathrm{dl})$ & $63.4 \pm 12.4$ \\
HbA1c (NGSP) & $(\%)$ & $5.3 \pm 0.3$ \\
Total protein & $(\mathrm{g} / \mathrm{dl})$ & $7.4 \pm 0.4$ \\
Albumin & $(\mathrm{g} / \mathrm{dl})$ & $4.8 \pm 0.3$ \\
Urea nitrogen & $(\mathrm{mg} / \mathrm{dl})$ & $12.8 \pm 2.8$ \\
Creatinine & $(\mathrm{mg} / \mathrm{dl})$ & $0.7 \pm 0.1$ \\
Na & $(\mathrm{mEq} / \mathrm{l})$ & $140.7 \pm 1.4$ \\
$\mathrm{~K}$ & $(\mathrm{mEq} / \mathrm{l})$ & $4.2 \pm 0.3$ \\
Cl & $(\mathrm{mEq} / \mathrm{l})$ & $104.4 \pm 1.5$ \\
Ca & $(\mathrm{mg} / \mathrm{dl})$ & $9.5 \pm 0.3$ \\
Pi & $(\mathrm{mg} / \mathrm{dl})$ & $4.0 \pm 0.4$ \\
Intact PTH & $(\mathrm{pg} / \mathrm{dl})$ & $42.8 \pm 12.4$ \\
\hline
\end{tabular}

Values are mean \pm SD. HbA1c; hemoglobin $\mathrm{A} 1 \mathrm{c}$, Na; sodium, $\mathrm{K}$; potassium, $\mathrm{Cl}$; chlorine, $\mathrm{Ca}$; calcium, $\mathrm{Pi}$; inorganic phosphorus.

Co. Ltd., Tokyo, Japan), which could accumulate 1/50th of whole urine, over a $24-\mathrm{h}$ monitoring period. Subjects were instructed to discard the first morning void and to collect all urine over the following 24-h, including the first void on the next morning. After weighing the total volume of urine samples, we dispensed them into storage vessels for storage at $4^{\circ} \mathrm{C}$ or $-30^{\circ} \mathrm{C}$ until use. The analysis company, SRL Inc, (Tokyo, Japan) measured urine nitrogen levels, urine creatinine levels and urine inorganic phosphorus levels.

We calculated the daily dietary intake, estimated from the urine collection (UC), of protein (UC-Pro) and phosphorus (UC-P). We calculated UC-Pro using Maroni's formula ${ }^{(16)}$ and UC-P based on a report that phosphorus absorption was about $65 \%{ }^{(18)}$

$$
\begin{aligned}
\text { UC-Pro }(\mathrm{g} / \text { day })= & {[\text { urine nitrogen }(\mathrm{g} / \text { day })+0.031 \times \text { body }} \\
& \text { weight }(\mathrm{kg})] \times 6.25(\text { Maroni's formula }) \ldots . .(1)
\end{aligned}
$$

$$
\text { UC-P }(\mathrm{mg} / \text { day })=\text { urine phosphorus excretion }(\mathrm{mg} / \text { day }) / 0.65
$$

Weighed dietary records. Subjects recorded all of the foods and beverages, excluding water, that they ingested using an electronic scale during the 24-h urine collection period. They were also required to take pictures of their meals. They were encouraged to hand in nutrition labels containing facts and ingredients of processed foods, such as commercially-supplied packed lunch and home-meal-replacements. When they handed in weighed dietary records, they were interviewed to clarify how they consumed their diet and any missing food items. Dietary intake was calculated from dietary records (DR) for protein (DR-Pro) and phosphorus (DR-P) using nutrition calculation software (Excel Eiyoukun ver. 4.5, Kenpakusya, Tokyo, Japan).

Anthropometric and biochemical examinations of blood. Height, body weight and body fat percentage were calculated using a bioelectrical impedance analysis method (TANITA TBF215; TANITA Corporation, Tokyo, Japan). Body mass index (BMI) was calculated using the following formula:

$$
\text { BMI }=\text { body weight }(\mathrm{kg}) / \text { body height }(\mathrm{m})^{2}
$$

Blood samples were dispensed into vacuum blood collection tubes and centrifuged $\left(4^{\circ} \mathrm{C}, 3,000 \mathrm{rpm}, 10 \mathrm{~min}\right)$ immediately.
Serum and plasma samples were separated and stored at $-30{ }^{\circ} \mathrm{C}$ until use. Clinical laboratory measures were levels taken of triglyceride (TG), low-density lipoprotein cholesterol (LDL-Cho), high-density lipoprotein cholesterol (HDL-Cho), hemoglobin Aic $\left(\mathrm{HbA}_{1} \mathrm{c}\right)$, total protein $(\mathrm{TP})$, albumin $(\mathrm{Alb})$, urea nitrogen $(\mathrm{UN})$, creatinine $(\mathrm{Cre})$, sodium $(\mathrm{Na})$, potassium $(\mathrm{K})$, chloride $(\mathrm{Cl})$, calcium $(\mathrm{Ca})$, phosphorus ( $\mathrm{S}-\mathrm{Pi})$, intact parathormone (iPTH) by the analysis company, SRL Inc.

Statistical analysis. Data were described as means \pm SD. The data were tested for normality using the Shapiro-Wilk test. All statistical analyses were performed with SPSS Statistic, ver. 19.0 for Windows (1989-2010, SPSS, Inc., an IBM Company, Chicago, IL) and were considered statistically significant at $p<0.05$.

Spearman's rank correlation coefficient was used to evaluate association between DR and UC for phosphorus and protein, and between phosphorus and protein of DR and UC. Wilcoxon signed rank test was used to compare means and the phosphorus-protein ratio between DR and UC. Pearson's correlation coefficient was used to evaluate association between the difference in DR and UC. Bland-Altman plots were used to evaluate the difference between DR and UC in further detail.

\section{Results}

The characteristics of the subjects are shown in Table 1. Mean age was $22.1 \pm 1.5$ years and body mass index was $21.1 \pm 2.6 \mathrm{~kg} / \mathrm{m}^{2}$. Subjects had normal glucose and lipid metabolism, hepatic function and renal function.

Positive correlations were observed between DR and UC for protein and phosphorus $(\mathrm{r}=0.553, \mathrm{r}=0.528$, respectively; $p<0.001$ ) (Fig. 1).

The average dietary protein intake from DR and UC was $71.1 \pm 27.1 \mathrm{~g} /$ day and $56.6 \pm 15.8 \mathrm{~g} /$ day, respectively $(p<0.001)$. The average phosphorus intake was $1,051 \pm 386 \mathrm{mg} /$ day and $943 \pm 323 \mathrm{mg} /$ day, respectively $(p<0.01)$. The average intakes from the DR were significantly higher than from UC for both protein and phosphorus (Fig. 2).

A positive correlation between protein and phosphorus was observed in the DR $(\mathrm{r}=0.930 ; p<0.001)$ and UC $(\mathrm{r}=0.833$; $p<0.01$ ) (Fig. $3 \mathrm{~A}$ and $\mathrm{B}$ ). We then analyzed the correlation between the difference in phosphorus and protein between DR and UC (DR-UC) and observed a significant positive correlation $(\mathrm{r}=0.745 ; p<0.001)$ (Fig. 3C).

Bland-Altman plots for protein and phosphorus are shown in Fig. 4A and B. The mean differences between DR and UC and their corresponding $95 \%$ CIs were $14.5 \mathrm{~g}, 10.1$ to 19.1 for protein and $108 \mathrm{mg}, 38$ to 179 for phosphorus. The data suggested a fixed bias and proportional bias for protein and phosphorus, respectively. Furthermore, we calculated a correction phosphorus value (CO-P) without the effect of DR-Pro, and analyzed the difference between CO-P and UC-P. However, the values did not show an exact match (mean difference $-96 ; 95 \% \mathrm{CI}-143$ to $-49 ; p<0.05$ ) (Fig. 4C).

Fig. 5 demonstrates the phosphorus-protein ratio. The phosphorus-protein ratio in DR was nearly 15 , and was significantly lower than the ratio in UC $(15.1 \pm 2.2 \mathrm{mg} / \mathrm{g}$, and $16.6 \pm 3.3 \mathrm{mg} / \mathrm{g}$, respectively; $p<0.001)$.

\section{Discussion}

There was a significant positive correlation between DR-Pro and UC-Pro and between DR-P and UC-P. Thus, it was suggested that dietary phosphorus intake could be estimated from the 24-h urine collection method. The average intake of both phosphorus and protein were significantly higher from DR compared with UC. In the present study, we estimated food intake using pictures, and interviews when subjects were unable to weigh the food. Even if the subjects were able to weigh the food, they may have failed to 

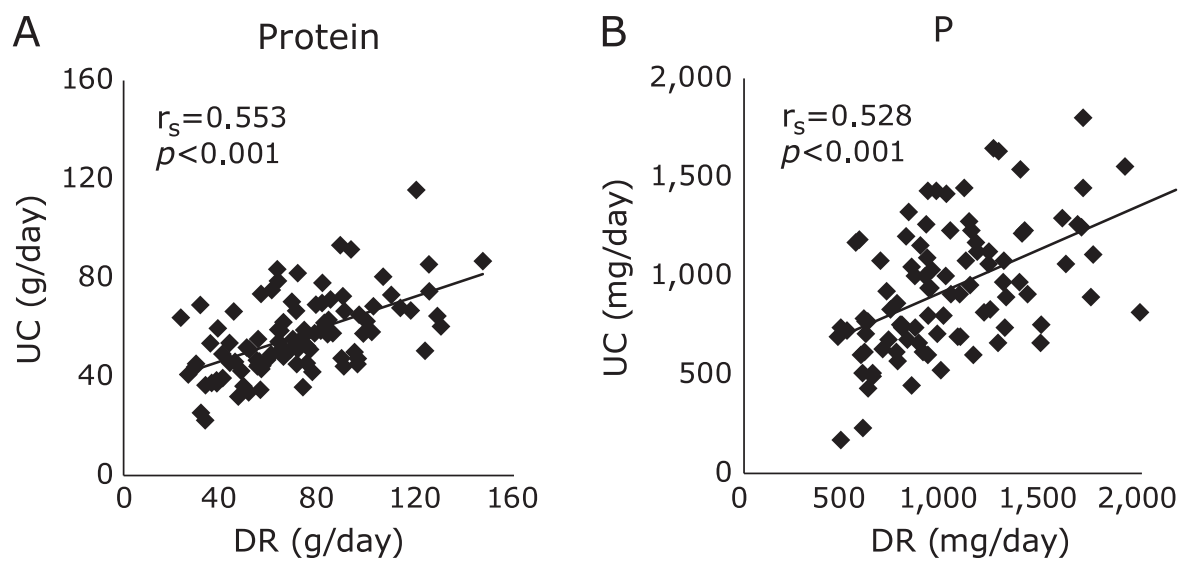

Fig. 1. Correlation between dietary record and 24-h urine collection. Correlation between dietary record (DR) and 24-h urine collection (UC) for protein $(A)$ and phosphorus $(P)(B)$. Spearman's correlation coefficients $\left(r_{s}\right)$ and their $p$ values for $r_{s}=0$ are presented for each association.
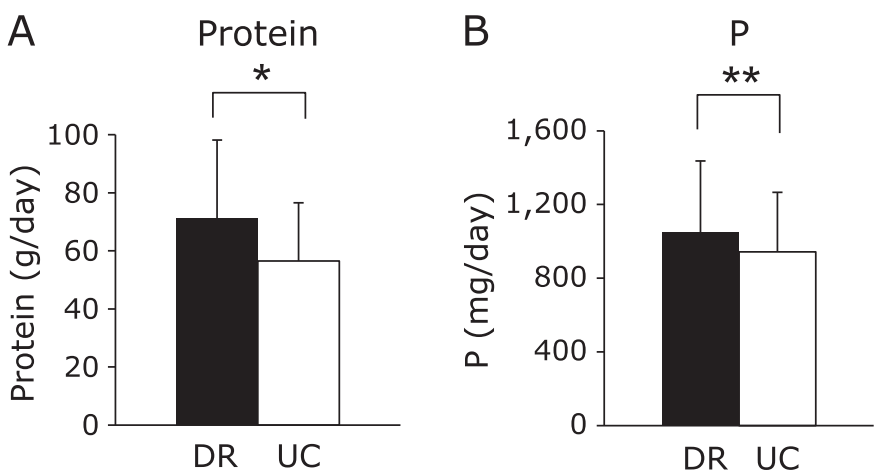

Fig. 2. Average protein and phosphorus intake in dietary record and 24-h urine collection. Values are mean $\pm S D$. Average intake in $D R$ and UC for protein (A) and phosphorus (P) (B). ${ }^{*} p<0.001,{ }^{*} p<0.01$ : DR vs UC by Wilcoxon signed-rank test. take account of the weight change during cooking. Thus, weighed dietary records can estimate the inaccuracy in food intake measurements. It is reported that people with a high BMI tend to underestimate how much they eat. ${ }^{(12)}$ In addition, the difference in dietary protein intake between weighed dietary records and 24-h urine collection tends to increase as people age. ${ }^{(13)}$ This has also been reported in type 2 diabetes. ${ }^{(14)}$ Based on the above, weighed dietary records are likely to cause errors dependant upon the characteristics of the subjects. Furthermore, the amount of phosphorus in foods isn't necessarily in agreement with food labels, ${ }^{(19)}$ and that's why there is a difference between weighed dietary records and 24-h urine collection.

It is reported that phosphate intake correlates with dietary protein intake. ${ }^{(8,9)}$ In the present study, there were significant positive correlations between DR-P and DR-Pro and between UC-P and UC-Pro. We suggest that the difference in phosphorus between DR and UC was affected by the difference in protein in these two groups. We analyzed the correlation between the difference in phosphorus and the difference in protein for DR and UC: we observed a significant positive correlation. Our results suggested that the difference in phosphorus was associated with the difference in protein in DR and UC.

Bland-Altman plots were performed to evaluate in further detail the difference in phosphorus and dietary protein intake between
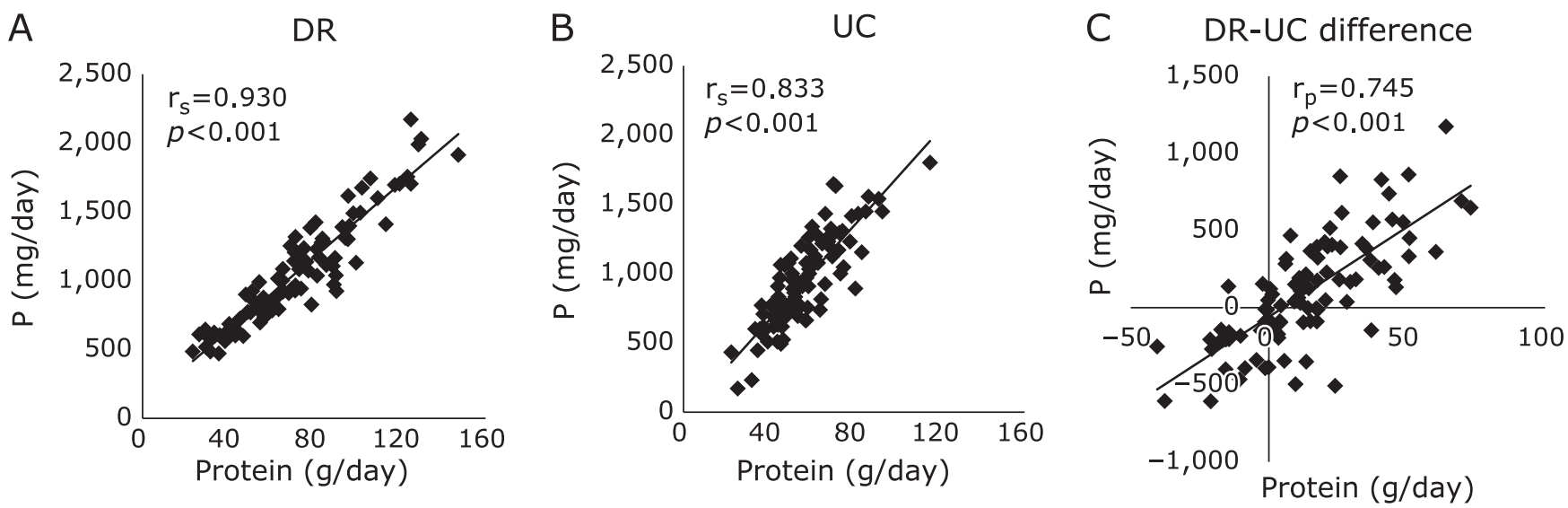

Fig. 3. Correlation between phosphorus and protein intake in each dietary record and 24-h urine collection and their differences. Correlation between phosphorus (P) and protein intake in each dietary record (DR) (A), and 24-h urine collection (UC) (B) and differences between DR and UC for protein and $P(C)$. Spearman's correlation coefficient $\left(r_{s}\right)$, Pearson's correlation coefficient $\left(r_{p}\right)$ and their $p$ value for $r_{s}=0$ and $r_{p}=0$ are presented for each association. 

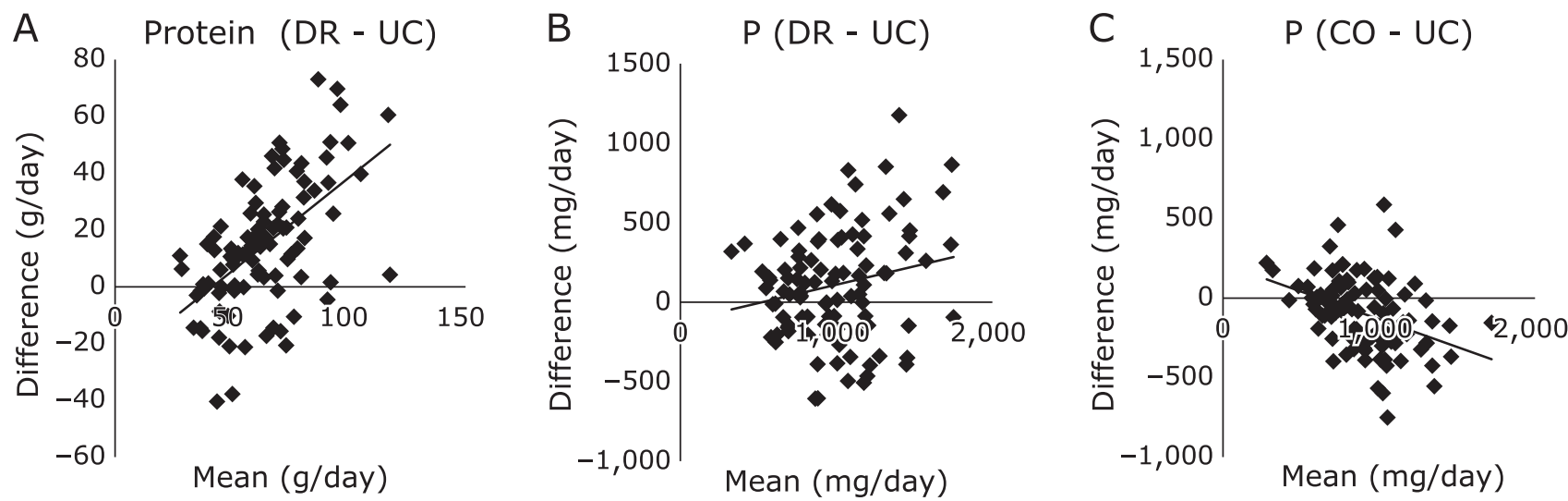

Fig. 4. Bland-Altman plots for dietary records, 24-h urine collection and correction value. Differences between protein and phosphorus $(P)$ intakes estimated from dietary records (DR) and 24-h urine collection (UC) (y-axis) plotted against the mean from the two methods ( $x$-axis) for protein $(D R-U C)(A)$, and P (DR-UC) (B) and the correction value (CO-UC) (C). Data are presented for the total study samples ( $\mathrm{n}: 32 \times 3$ days $=96)$.

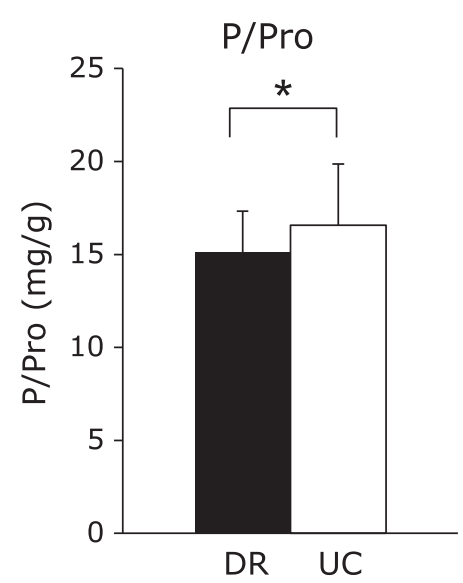

Fig. 5. Phosphorus-protein ratios (P/Pro) for the dietary record and 24-h urine collection. Average phosphorus-protein ratio for DR and UC. Values are mean $\pm S D$. * $p<0.001$ DR vs UC by Wilcoxon signed-rank test.

DR and UC. The mean differences in both dietary phosphorus intake and dietary protein intake between DR and UC had significant positive biases. We suggest this was most likely caused by estimation error in the DR. In addition, the observed proportional error which showed greater intake of protein or phosphorus, produced a larger difference between DR and UC. It has been reported that differences in dietary protein intake between weighed dietary records and urine collections increased with increasing amounts of dietary protein intake. ${ }^{(13)}$ The present study suggested that the difference in protein and phosphorus intake between DR and UC increases when their intakes increase. Although we calculated CO-P without the effect of DR-Pro, and analyzed the difference between CO-P and UC-P, there still remained both a fixed bias and proportional bias, suggesting that the difference in phosphorus intakes between DR and UC is affected not only by protein differences but other factors. Previous studies have reported that boiled foods were significantly lower in dietary phosphorus than raw foods, ${ }^{(9)}$ and the nutritional content of food changes with the seasons and area of production. ${ }^{(20)}$ These factors may cause differences in phosphorus between weighed dietary records and urine collections.

To evaluate what caused the differences in phosphorus intake between DR and UC, we focused on the phosphorus-protein ratio. The phosphorus-protein ratio is approximately $15 \mathrm{mg} / \mathrm{g}$ in natural foods ${ }^{(8,9)}$ In the present study, the phosphorus-protein ratios in UC were significantly higher than those in DR. We hypothesized there were two reasons for this: first, food additives such as preservatives and $\mathrm{pH}$ adjusters which contain phosphate may be used in processed foods (disodium phosphate, sodium acid pyrophosphate). ${ }^{(19)}$ Recently, dietary phosphorus intake from food additives has rapidly increased. (21) Phosphorus derived from food additives weren't included in the weighed dietary records which is why phosphorus-protein ratios in DR were lower than those in UC. The second reason may be the difference in phosphorus absorption rates. ${ }^{(23,24)}$ Dietary phosphorus has two main sources: one is organic, including animal and vegetarian protein, the other is inorganic, mostly food preservatives. Inorganic phosphorus is presented as a salt that more readily disassociates and is more readily absorbed than organic phosphorus in the intestine. ${ }^{(25)}$ In addition, it is reported that animal and vegetable phosphorus absorption rates differ: in patients with advanced chronic kidney disease (CKD), serum phosphorus levels were lower after eating a vegetable protein diet compared with animal protein. ${ }^{(23)}$ Dietary animal-derived or supplement-derived serum phosphorus levels and urinary phosphorus excretion were significantly higher than plant-derived levels in healthy individuals. ${ }^{(24)}$ Dietary phosphorus intakes could be estimated from the 24-h urine collection method used in this study but it could not be estimated from weighed dietary records because it is unable to take into account differences in absorption rates. In maintenance hemodialysis patients, phosphorus absorption was reduced as calcium intake increased, (26) suggesting that phosphorus absorption depends on the balance with calcium intake.

Previous study indicated that urinary phosphorus excretion decrease with decreasing renal function in patients with $\mathrm{CKD}$, especially creatinine clearance $(\mathrm{CCr})<30 \mathrm{ml} / \mathrm{min} .{ }^{(27)}$ The progressive deterioration of renal function leads to retention of phosphorus, and alterations of several phosphorus regulating hormones such as PTH, fibroblast growth factor 23, 1, 25-hydroxyvitamin $\mathrm{D}_{3}$ and Klotho. ${ }^{(28,29)}$ Our study was limited to healthy subjects (CCr: $120.7 \pm 22.4 \mathrm{ml} / \mathrm{min}$ ), so we need additional research in subjects with various renal function to make use of estimating of dietary phosphorus intake using 24-h urine collection widely available.

In conclusion, we suggest that the 24-h urine collection method can estimate the amount of dietary phosphorus intake, and it is a superior method to using weighed dietary records. Further studies on phosphorus absorption and interaction with other nutrients are now required. 


\section{Acknowledgments}

This work was supported by Grants-in-Aid for Scientific Research from the Ministry of Education, Culture, Sports, Science and Technology in Japan (for MS, HA).

\section{Abbreviations}

BMI body mass index

$\mathrm{Ca} \quad$ calcium

$\mathrm{CCr} \quad$ creatinine clearance

CKD chronic kidney disease

$\mathrm{Cl} \quad$ chloride

CO-P correction phosphorus

Cre creatinine

DR dietary intake estimated from dietary records

DR-P phosphorus intake estimated from DR

DR-Pro protein intake estimated from DR

\section{References}

1 Sarnak MJ, Levey AS, Schoolwerth AC, et al. Kidney disease as a risk factor for development of cardiovascular disease: a statement from the American Heart Association Councils on Kidney in Cardiovascular Disease, High Blood Pressure Research, Clinical Cardiology, and Epidemiology and Prevention. Circulation 2003; 28: 2154-2169.

2 Jungers P, Massy ZA, Nguyen Khoa T, et al. Incidence and risk factors of atherosclerotic cardiovascular accidents in predialysis chronic renal failure patients: a prospective study. Nephrol Dial Transplant 1997; 12: 2597-2602.

3 Noori N, Kalantar-Zadeh K, Kovesdy CP, Bross R, Benner D, Kopple JD. Association of dietary phosphorus intake and phosphorus to protein ratio with mortality in hemodialysis patients. Clin J Am Soc Nephrol 2010; 5: 683-692.

4 Block GA, Hulbert-Shearon TE, Levin NW, Port FK. Association of serum phosphorus and calcium $\mathrm{x}$ phosphate product with mortality risk in chronic hemodialysis patients: a national study. Am J Kidney Dis 1998; 31: 607-617.

5 Nishida Y, Taketani Y, Yamanaka-Okumura H, et al. Acute effect of oral phosphate loading on serum fibroblast growth factor 23 levels in healthy men. Kidney Int 2006; 70: 2141-2147.

6 Shuto E, Taketani Y, Tanaka R, et al. Dietary phosphorus acutely impairs endothelial function. J Am Soc Nephrol 2009; 20: 1504-1512.

7 Ministry of Agriculture, Forestry and Fisheries (MAFF) 2013. Food balance sheet in Japan (in Japanese). MAFF, Tokyo. (http://www.maff.go.jp/index.html)

8 Boaz M, Smetana S. Regression equation predicts dietary phosphorus intake from estimate of dietary protein intake. J Am Diet Assoc 1996; 96: 12681270 .

9 Cupisti A, Comar F, Benini O, et al. Effect of boiling on dietary phosphate and nitrogen intake. J Ren Nutr 2006; 16: 36-40.

10 Kenko Eiyo Joho Kenkyukai. The National Health and Nutrition Survey in Japan, 2008. Tokyo: Daiichi-syuppan, 2011; 84 (in Japanese).

11 Ministry of Health, Labour and Welfare (MHLW) 2010 edition. Dietary Reference Intakes in Japan. MHLW, Tokyo: Daiichi-syuppan, 2009; app. 48 (in Japanese).

12 Okubo H, Sasaki S. Underreporting of energy intake among Japanese women aged 18-20 years and its association with reported nutrient and food group intakes. Public Health Nutr 2004; 7: 911-917.

13 Bokhof B, Günther AL, Berg-Beckhoff G, Kroke A, Buyken AE. Validation of protein intake assessed from weighed dietary records against protein estimated from $24 \mathrm{~h}$ urine samples in children, adolescents and young adults participating in the Dortmund Nutritional and Longitudinally Designed (DONALD) Study. Public Health Nutr 2010; 13: 826-834.

14 Vaz JS, Bittencourt M, Almeida JC, Gross JL, De Azevedo MJ, Zelmanovitz T. Protein intake estimated by weighed diet records in patients with type 2 diabetes: misreporting and intra-individual variability using 24-hour nitrogen output as criterion standard. J Am Diet Assoc 2008; 108: 867-872.

15 Ministry of Health, Labour and Welfare (MHLW) 2009. Nutrition Labeling
$\mathrm{HbA1c}$

HDL-Cho high-density lipoprotein cholesterol

iPTH intact parathormone

$\mathrm{K} \quad$ potassium

LDL-Cho low-density lipoprotein cholesterol

$\mathrm{Na} \quad$ sodium

$\mathrm{S}-\mathrm{Pi} \quad$ serum phosphorus

TG triglyceride

$\mathrm{TP} \quad$ total protein

UC dietary intake estimated from urine collection

UC-P phosphorus intake estimated from UC

UC-Pro protein intake estimated from UC

UN urea nitrogen

\section{Conflict of Interest}

No potential conflicts of interest were disclosed.
Standards (in Japanese). MHLW, Tokyo. (http://www.mhlw.go.jp/)

16 Maroni BJ, Steinman TI, Mitch WE. A method for estimating nitrogen intake of patients with chronic renal failure. Kidney Int 1985; 27: 58-65.

17 Arcand J, Floras JS, Azevedo E, Mak S, Newton GE, Allard JP. Evaluation of 2 methods for sodium intake assessment in cardiac patients with and without heart failure: the confounding effect of loop diuretics. Am J Clin Nutr 2011; 93: 535-541.

18 Tonelli M, Pannu N, Manns B. Oral phosphate binders in patients with kidney failure. $N$ Engl J Med 2010; 362: 1312-1324.

19 Sullivan CM, Leon JB, Sehgal AR. Phosphorus-containing food additives and the accuracy of nutrient databases: implications for renal patients. $J$ Ren Nutr 2007; 17: 350-354.

20 Science and Technology Agency. Standard tables of Food-composition in Japan. 5th revised and enlarged ed. Tokyo: Printing Bureau of the Ministry of Finance, 2005; 6 (in Japanese).

21 Karalis M, Murphy-Gutekunst L. Patient education. Enhanced foods: hidden phosphorus and sodium in foods commonly eaten. J Ren Nutr 2006; 16: 79 81.

22 Benini O, D'Alessandro C, Gianfaldoni D, Cupisti A. Extra-phosphate load from food additives in commonly eaten foods: a real and insidious danger for renal patients. J Ren Nutr 2011; 21: 303-308.

23 Moe SM, Zidehsarai MP, Chambers MA, et al. Vegetarian compared with meat dietary protein source and phosphorus homeostasis in chronic kidney disease. Clin J Am Soc Nephrol 2011; 6: 257-264.

24 Karp HJ, Vaihia KP, Kärkkäinen MU, Niemistö MJ, Lamberg-Allardt CJ. Acute effects of different phosphorus sources on calcium and bone metabolism in young women: a whole-foods approach. Calcif Tissue Int 2007; 80: 251-258.

25 Uribarri J, Calvo MS. Hidden sources of phosphorus in the typical American diet: does it matter in nephrology? Semin Dial 2003; 16: 186-188.

26 Heaney RP, Nordin BE. Calcium effects on phosphorus absorption: implications for the prevention and co-therapy of osteoporosis. J Am Coll Nutr 2002; 21: 239-244.

27 Houston J, Smith K, Isakova T, Sowden N, Wolf M, Gutiérrez OM. Associations of dietary phosphorus intake, urinary phosphate excretion, and fibroblast growth factor 23 with vascular stiffness in chronic kidney disease. $J$ Ren Nutr 2013; 23: 12-20.

28 Shigematsu T, Kazama JJ, Yamashita T, et al. Possible involvement of circulating fibroblast growth factor 23 in the development of secondary hyperparathyroidism associated with renal insufficiency. Am J Kidney Dis 2004; 44: 250-256.

29 Pavik I, Jaeger P, Ebner L, et al. Secreted Klotho and FGF23 in chronic kidney disease Stage 1 to 5: a sequence suggested from a cross-sectional study. Nephrol Dial Transplant 2013; 28: 352-359. 